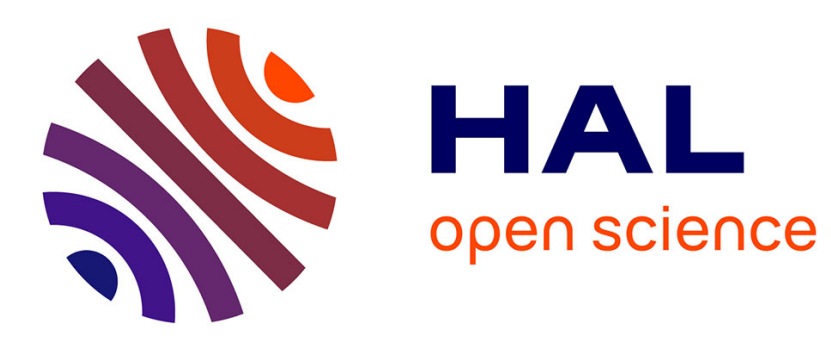

\title{
Multiagent Decision Making for SME Supply Chain Simulation
}

\author{
Jihène Tounsi, Julien Boissiere, Georges Habchi
}

\section{To cite this version:}

Jihène Tounsi, Julien Boissiere, Georges Habchi. Multiagent Decision Making for SME Supply Chain Simulation. ECMS2009, Jun 2009, Madrid, Spain. pp. 203-211. hal-00403807

\section{HAL Id: hal-00403807 \\ https://hal.univ-smb.fr/hal-00403807}

Submitted on 8 Jan 2013

HAL is a multi-disciplinary open access archive for the deposit and dissemination of scientific research documents, whether they are published or not. The documents may come from teaching and research institutions in France or abroad, or from public or private research centers.
L'archive ouverte pluridisciplinaire HAL, est destinée au dépôt et à la diffusion de documents scientifiques de niveau recherche, publiés ou non, émanant des établissements d'enseignement et de recherche français ou étrangers, des laboratoires publics ou privés. 


\section{MULTIAGENT DECISION MAKING FOR SME SUPPLY CHAIN SIMULATION}

\author{
Jihene Tounsi \\ Université de Savoie \\ SYMME-Polytech'Savoie \\ 12, chemin de Bellevue, \\ BP80439 \\ 74940, Annecy-Le-Vieux \\ Jihene.tounsi@univ-savoie.fr
}

\author{
Julien Boissière \\ Université de Savoie \\ LISTIC-Polytech'Savoie \\ 12, chemin de Bellevue, \\ BP80439 \\ 74940, Annecy-Le-Vieux \\ Julien.boissiere@univ-savoie.fr
}

\author{
Georges Habchi \\ Université de Savoie \\ SYMME-Polytech'Savoie \\ 12, chemin de Bellevue, \\ BP80439 \\ 74940, Annecy-Le-Vieux \\ Georges.habchi@univ-savoie.fr
}

\section{KEYWORDS}

Small and Medium Enterprises (SMEs), Supply chain, multiagent, modelling, reactive monitoring.

\begin{abstract}
To tackle the complexity and heterogeneity of the networks that integrate Mechatronic SMEs, this paper describes a modelling and simulation solution based on multiagent system and ArchMDE (Architecture Model Drive Engineering) methodology for supply chain agentification. This research work outlines two main results: conceptualisation and modelling. The first one deals with the identification and concepts definition of the different entities moving and acting into the multiagent and supply chain systems. The second one discusses the agent approach providing a framework naturally oriented to model supply chain concepts and their dynamic behavior.
\end{abstract}

\section{INTRODUCTION}

The Supply chain concept has become a major stake in today's industrial context. In order to meet the dynamic global market and its requirements, Small and Medium Enterprises (SMEs) must integrate supply chain practices in their own complex network [Villarreal Lizarraga et al., 2005; Julien, 1997].

In the French region of Savoie, the industrial environment is mostly composed of particular SMEs specialized in mechatronics. Very often, these companies collaborate in a cluster to achieve a task in the global supply chain. Indeed, according to some investigations and studies on the environment, three major features of the supply chain which integrates SMEs cluster and especially mechatronic ones [Tounsi et al., 2008] arose. Firstly, supply chain in this context is a complex system. This complexity is due to the high number of autonomous actors and SME networks which collaborate to achieve a given process. Secondly, the studied SMEs are not necessarily located in the same geographical area as the other nodes of the supply chain. And finally, as a result of the two previous characteristics, SMEs face a lack of visibility in the global supply chain. Thus, the studied supply chain is divided in many sites spread over several geographic locations depending on their purpose or activity in the global supply chain. These sites only have a local visibility but are coordinated with other sites through the product flows. For all these reasons, studying the structure and the behaviour of the supply chain in the SMEs mechatronic field has became a challenge and a growing need was expressed by manufacturers in Savoie.

This paper proposes a modelling solution based on multiagent paradigm. The benefits of multiagent systems (MAS) are widely recognized in literature. Agent technology allows new approach for the modelling and simulation of complex distributed systems. Hence, on one hand, autonomous agents can communicate their preferences, deal objectives with other agents or coordinate together to reach their own objectives or some more global objectives [Bussman et al., 2004]. On another hand, the supply chain is composed by actors or entities which evolve in an organization and interact to achieve a collective purpose. This analogy leads to multiagent approach being a framework naturally oriented to model the supply chain.

To introduce the modelling solution, the first section of the article focuses on the different approaches that were adopted to generate the agentified domain metamodel. Then, we introduce the developed concepts of the supply chain in SMEs context and the multiagent ones and their merger one. In the last section, the dynamic reactive behaviour of the metamodel is introduced before a conclusion is drawn.

\section{APPROACH AND CONCEPTUAL METHODOLOGY}

The aim of this paper is to present the application of multiagent system to model the dynamic behaviour of the supply chain in the SMEs context. To reach this purpose, let us first introduce the adopted development process and the conceptual modelling methodology to generate the domain metamodel. 


\section{ArchMDE Development Process}

ArchMDE (Architecture Model Drinvein Engineering) is a development process proposed within a $\mathrm{PhD}$ research work [Azaiez, 2007].

The approach is based on Model-Driven Engineering (MDE) [Kent, 2002] which promoted the separation and combination of models in order to control the software development in its different phases (from the analysis to the implementation). One of the main important issues in MDE approach is the metamodelling one. The metamodel defines the domain concepts, their relationships and their properties. All produced models have to be conform to the metamodel.

In our research context, we identify two metamodels related to AchMDE approach. The first one describes functional concepts and properties of SMEs Mechatronic supply chain. The second one defines a multiagent metamodel. A combination of the two metamodels will generate an agentified domain metamodel. On the basis of the agentified metamodel, different functional models will be described to introduce the functionalities of the system (Figure 1). Finally, the use of a platform metamodel is necessary to generate the program code.

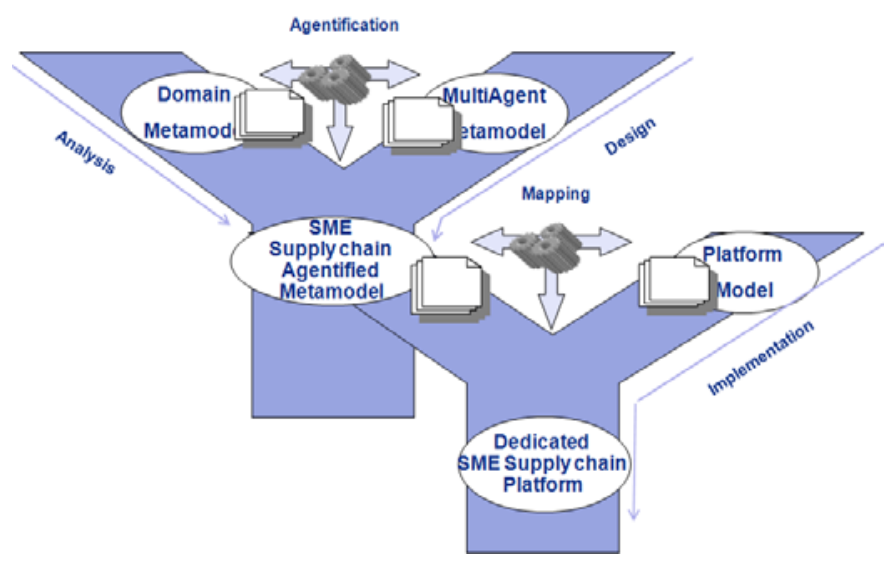

Figure 1. ArchMDE development process [Tounsi et al., 2009]

In this paper, we describe the first phase of the ArchMDE development process. Therefore, in the following subsections, we introduce the adopted conceptual modelling methodology used to generate the domain metamodel.

\section{Conceptual Modelling Methodology}

To identify the concepts and properties of the supply chain in SMEs mechatronic domain, a conceptual methodology is developed. This methodology is an incremental one based on three main visions [Tounsi et al., 2008]: product vision, structure vision and process vision.
In each step, a vision is applied to build or to refine the conceptual model. The result of each step is an intermediary model considered as the input for the next one. Therefore, at the end of the 3 steps, a final architecture of the conceptual model is obtained.

- The Product Vision considers the supply chain dedicated to a particular product (or a family of a product) from the raw materials to the final goods [Thierry, 2003]. It focuses on the product flow to define the environment and organizations implicated in its management. The environment is characterized by the circulation of the physical flow and the different steps of product transformation as well as the related disturbances. The organizations are entities carrying out one or several activities. In the studied context, the organizations are SME mechatronic that collaborate to accomplish one or several tasks. In our context, the product vision builds the first abstract model of the supply chain.

- The Structure Vision has been proposed by Cooper et al. [Cooper et al., 1997]. It considers the architecture of the supply chain composed of: actors (decision-making actors and synchronization actors), network structure (roles in the network and the number of actors in each role) and relationship characteristics between actors. On the basis of the abstract model provided by the previous step, the Structure Vision details the involved organizations and the physical environment. At the end of this step, an intermediary conceptual model is obtained.

- The Process Vision is based on the classification of processes according to the decision-making level [Chopra and Meindl, 2001; Stevens, 1989]: strategic, tactical and operational. While applying Process Vision, various categories of processes are identified and integrated to the previous intermediate model. This can be done according to decision level but also depending on the actors' relationships. These relationships can be classified into two categories: (i) management and control process (ii) synchronization of information and physical flow according to a predefined process scheme. At this last step, a refined conceptual model is generated.

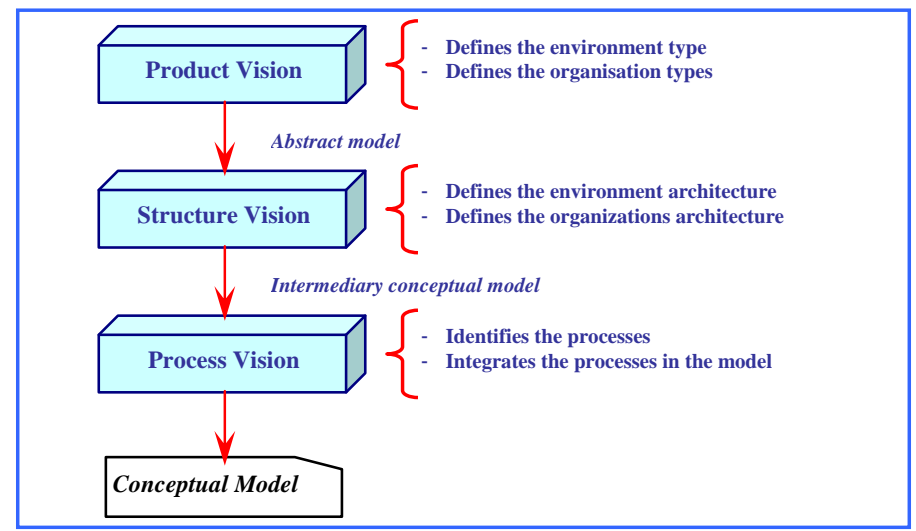




\section{Figure 2. Conceptual Modelling Methodology \\ Framework [Tounsi et al., 2008] DOMAIN METAMODEL AGENTIFICATION}

The first phase of ArchMDE development process consists in the definition and combination of the domain metamodel and multiagent one. Then, main results of this step are outlined in this section. More details can be found in Tounsi et al. [Tounsi et al., 2009].

\section{Domain Metamodel}

By applying the proposed conceptual modelling methodology, the main concepts, architecture and processes are identified. The domain metamodel is a representation of these concepts using UML notation (a semi-formal Unified Modelling Language). Each concept is identified through a methodology step. Hence, the final metamodel is depicted in figure 3; each step beings represented in a block.

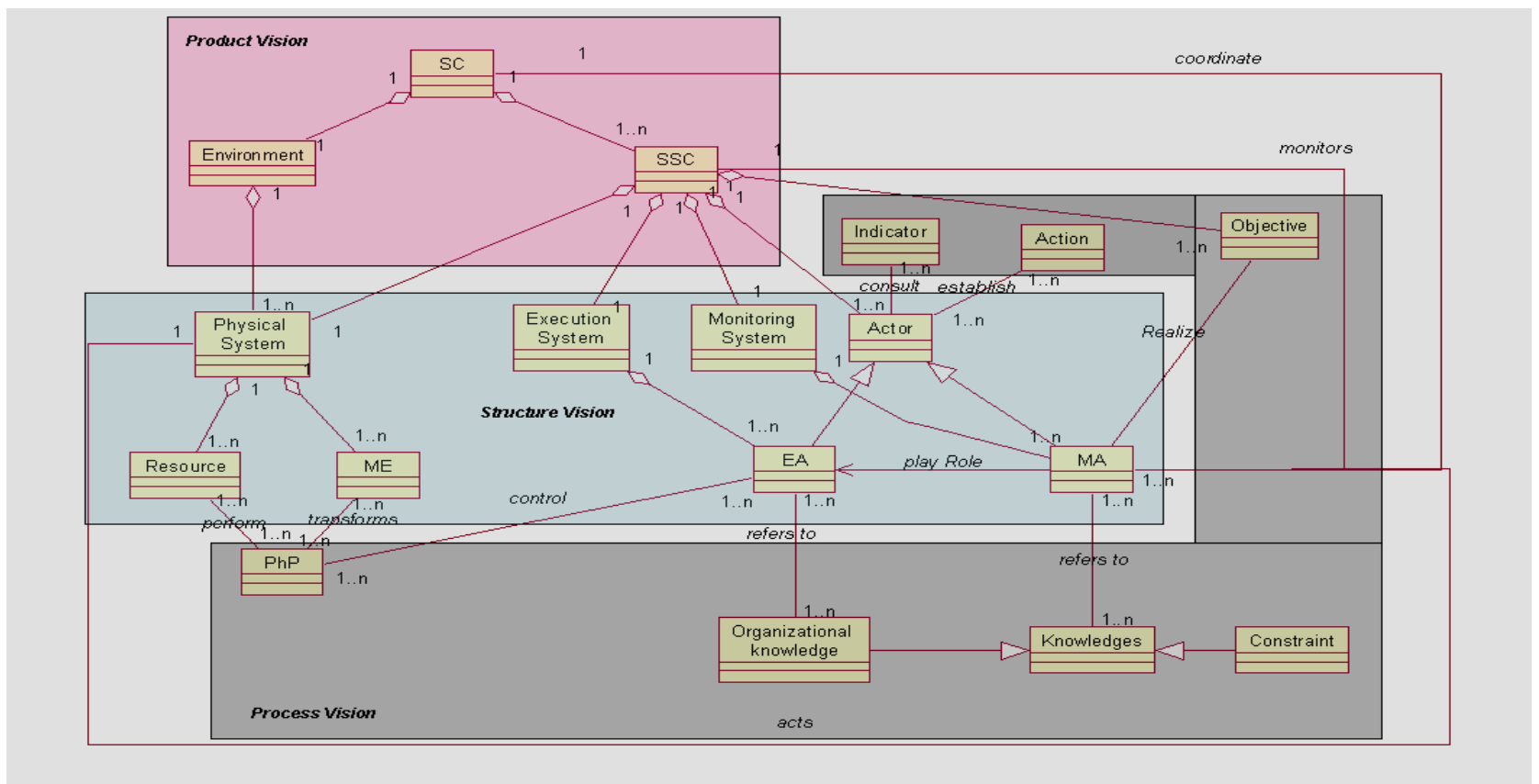

Figure 3. Domain metamodel

The first block is the group of concepts that are generated in the Product Vision. They define the abstract metamodel composed of:

- Supply chain (SC): this concept defines the root of the domain modelling. All other concepts will detail this concept.

- Environment: this concept models the space allocated to the product flow and management through the internal resources as well as the external elements able to influence the activities of the supply chain.

- Sub Supply Chain (SSC): the SSC represents a group of SME which collaborate to achieve an internal aim and/or the overall objective of the supply chain. The SSC is responsible for the management of the product flow in a certain stage of its life cycle.

The application of the Structure Vision results in the refinement of the first abstract model. As outlined in the previous section, these concepts define, on one hand, the network structure according to the decision level, and on the other hand, the actors' type according to their role. Structure vision leads us to identify SSC and Environment architecture. This structure is composed of 3 layers which involve particular concepts and play a specific role:
- The Monitoring System models the intelligent layer of the SSC. It controls and monitors the two other layers through the information provided by the Execution System. Monitoring Actors (MA) are the main elements of this layer. They model the intelligent actors of SSC and establish metrics to evaluate the performance of the group and consequently act on the two other layers. Therefore, MA are the components responsible for the control and decision-making in SSC but also for the coordination activity in the global supply chain.

- The Execution System is the reactive layer of the SSC. It deals with two main roles: (i) it ensures the synchronization of the physical flow according to the information gathered from the Physical System, (ii) it observes and corrects the Physical System if a perturbation occurs. In abnormal situations, the Execution System refers to the Monitoring System for coordination and decision-making. Executive Actors (EA) are the principal entities of this layer. EA mainly models the reactive actors and occasionally MA having reactive behaviour in this layer.

- The Physical System is the visible part of the environment from the SSC. It corresponds to the influence perimeter of the SSC. This layer is composed of passive elements controlled by the two other layers of the SSC. Two main concepts are identified: the Moving Entity (ME) modelling the product in 
circulation and the Resource modelling production means.

At the end of this step, an intermediary metamodel is obtained. Finally it's refined by applying the Process Vision. The last block contains these concepts:

- The Physical Process (PhP) describes the sequences of processing stages of the product. $\mathrm{PhP}$ is a concept to be integrated within a domain metamodel in order to define the tasks that can be handled by the Execution System.

- The Indicator Base represents a database storing the indicator measures. The EA detects Physical System deviation according to the gathered information within this database.

- The Action Base represents a database that stores the actions to apply when facing an indicator deviation.

- The Objective models the global goals of the supply chain or of the SSC ones.

- The Knowledge Base represents a database including all knowledge needed by the actors to make the right decision. Knowledge Base can be an organizational knowledge or a constraint.
- The Organizational Knowledge is an actor's database that stores information about his acquaintances(others actors in the system).

- The Constraint is a variable that an actor must consider to reach the global supply chain goal or the SSC's one.

Thereby, the development of these 3 steps of conceptual modelling methodology, generates a metamodel describing the studied domain regardless the computer technologies. This metamodel is the first artefact of ArchMDE development process.

\section{Multiagent Metamodel}

The second artefact to specify concerns the software engineering approach. In this section, we present the multiagent metamodel proposed by Azaiez [Azaiez, 2007] according to the "vowel approach". Indeed, Demazeau [Demazeau, 1996] defines the multiagent system as a set of four main views named "vowel approach":

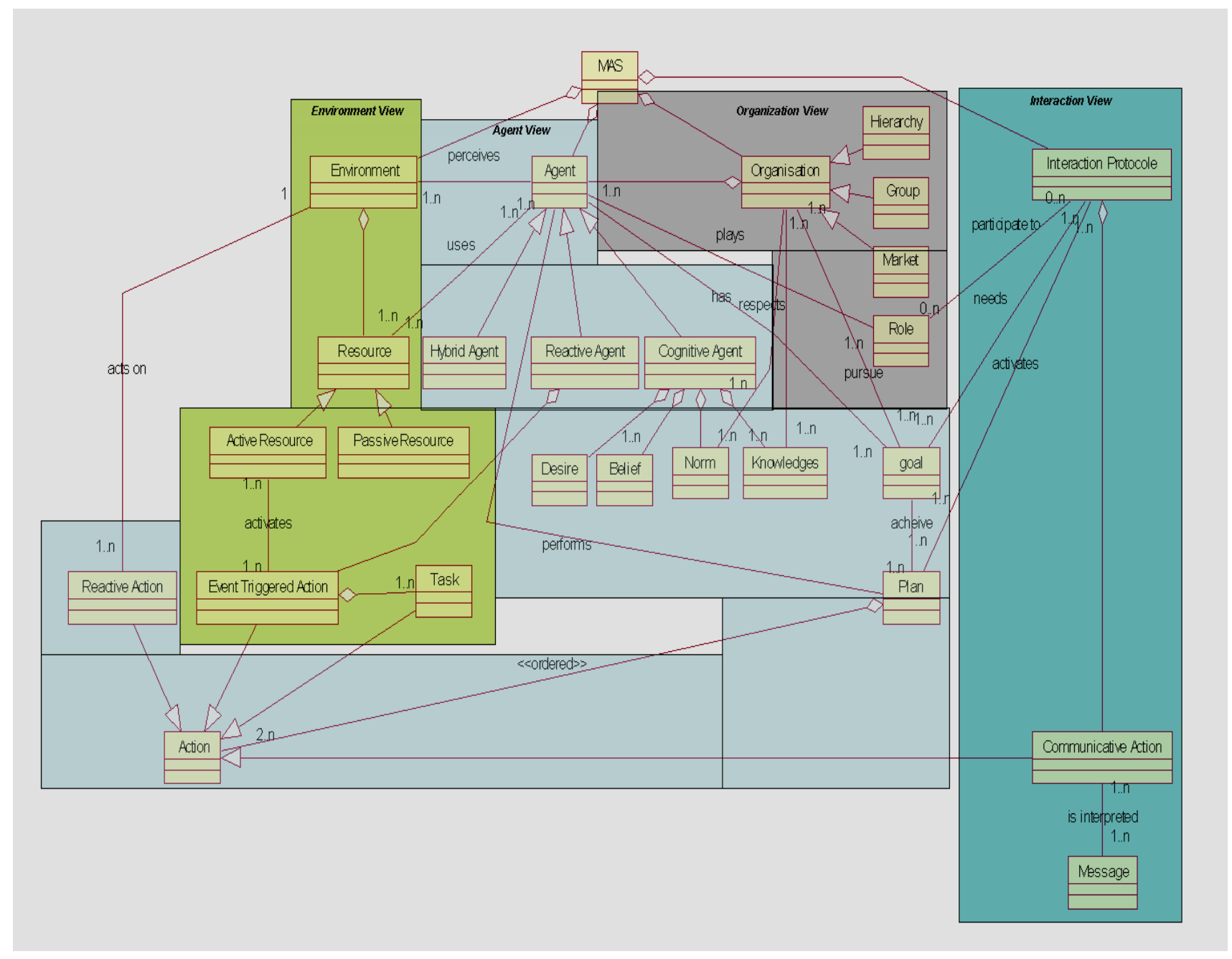

Figure 4. Multiagent metamodel [Azaiez, 2007] 
- Agent view (A): describes the internal structure of an agent. An agent is a computer system able to act autonomously in a given environment in order to meet the design objectives [Wooldridge, 2002]. The scientific community distinguishes three kinds of agent according to their decision-making model and intelligence degree. (i) The reactive agents that react to changes through predefined actions [Brooks, 1991]. (ii) The cognitive agents that have a reasoning faculty and the ability to choose the adequate action in order to achieve an optimal specific goal. This kind of agent also has a learning faculty enabling it to evolve in a decisionmaking system such as BDI agent [Wooldridge, 1999; Bratman et al., 1998]. (iii) The hybrid agent, which is a crossover between the reactive agent and the cognitive agent [Fischer et al., 1995].

- Environment view (E): describes the environment in which evolves the agent. FIPA (Federation of Intelligent Physical Agents) specification defined it as "...all that is external to the agent". According to Azaiez et al. [Azaiez et al., 2007b], the environment view can define two different kinds of environment: the simulated one and the deployed one. The simulated environment is a computer representation of an actual environment. It is generally modelled by a metric. The deployed environment deals with computers and appliances in which agents can be deployed, as well as resources that the agent can use. In the context of deployed environments, resources correspond to databases, indicators, variables, etc.

- Interaction view (I): describes the dynamic relationship between agents through protocols or interaction language. This interaction is a structured exchange of messages according to the internal state of the agent and the kind of the interaction framework (coordination, collaboration, cooperation or negotiation).

- Organization view $(\mathrm{O})$ : describes the structure of the whole system in terms of agent groups, hierarchy, relationships and the structure of the other entities which constitute the environment.

AEIO approach decomposes the whole multiagent system in several modules. This modularity facilitates the reuse of the different modules according to requirements.

\section{Domain Metamodel Agentification}

This step of the ArchMDE methodology consists in merging the multiagent metamodel with the domain one. This combination provides an agentified supply chain metamodel in SMEs field. Hence, a correspondence between the multiagent and the domain concepts is carried out according to their properties and roles in the metamodel. The table 1 summarizes this correspondence.
Table 1 Correspondence between Domain and Multiagent concepts

\begin{tabular}{|l|l|}
\hline \multicolumn{1}{|c|}{ Domain concepts } & \multicolumn{1}{|c|}{ Multiagent concepts } \\
\hline Supply Chain (SC) & MAS \\
\hline Environment & Environment \\
\hline Physical System & Resource \\
\hline Resource & Passive Resource \\
\hline $\begin{array}{l}\text { Moving Entity } \\
\text { (ME) }\end{array}$ & Active Resource \\
\hline $\begin{array}{l}\text { Physical Process } \\
\text { (PhP) }\end{array}$ & Task \\
\hline $\begin{array}{l}\text { Sub Supply Chain } \\
\text { (SSC) }\end{array}$ & Organization \\
\hline Monitoring System & Group \\
\hline Execution System & Group \\
\hline Actor & Agent \\
\hline $\begin{array}{l}\text { Executive Actor } \\
\text { (EA) }\end{array}$ & $\begin{array}{l}\text { Reactive Agent with executive } \\
\text { role }\end{array}$ \\
\hline $\begin{array}{l}\text { Monitoring Actor } \\
\text { (MA) }\end{array}$ & $\begin{array}{l}\text { Cognitive Agent with monitoring } \\
\text { and / or coordination role }\end{array}$ \\
\hline Objective & Goal \\
\hline Indicator & Belief \\
\hline Action & Plan \\
\hline Knowledge & Knowledge \\
\hline $\begin{array}{l}\text { Organizational } \\
\text { knowledge }\end{array}$ & Knowledge \\
\hline Constraint & Knowledge \\
\hline
\end{tabular}

\section{DYNAMIC BEHAVIOUR WITHIN THE SSC'S EXECUTION SYSTEM}

The SSC represents a SMEs network collaborating to reach a local objective. In the execution system, the collaborative process takes place in the following scenarios [Tounsi et al., 2009]:

- Physical system synchronization: in the "Execution System" of the SSC, actors will synchronize their information and their actions. This collaboration is frequent in the SSC in commonly encountered situations.

- Physical system control: the control of the physical system of the SSC will be based on the performance evaluation and the resolution of usual perturbations.

This section describes the reactive dynamic behaviour of the execution system within the SSC through the integration of communication protocols in the agentified domain metamodel. In literature, several protocols extend the Cooperative Problem Solving model (CPS) proposed by Wooldridge and Jennings [Wooldridge and Jennings, 1999]. The CPS defines an abstract way to structure a collective decision-making process in which a group of autonomous agents choose to work together to achieve a common goal. In more details, this model is deployed in four stages: 
- Recognition: in which an agent identifies the potential for cooperation.

- Team formation: in which an agent solicits assistance.

- Plan formation: in which the newly formed collective attempts to construct an agreed joint plan.

- Execution: in which members of the collective play out the roles they have negotiated.

The following subsection describes different collaboration processes to implement in the execution system of the proposed metamodel. These protocols follow the CPS abstract model.

\section{Physical Process Synchronization Protocol}

According to the metamodel, the Execution system is responsible for the synchronization of the physical process $(\mathrm{PhP})$ in common situations. Indeed, Executive actors (EA) which are reactive agents, synchronise $\mathrm{PhP}$ taking into account resources availability. Table 2 summerizes these agentified domain concepts and their role in this protocol.

Table 2. Role of the concepts in physical system synchronization

\begin{tabular}{|c|c|c|}
\hline $\begin{array}{l}\text { Domain } \\
\text { concepts }\end{array}$ & $\begin{array}{c}\text { Multiagent } \\
\text { equivalent }\end{array}$ & Role in the protocol \\
\hline EA & $\begin{array}{l}\text { Reactive } \\
\text { agent with } \\
\text { executive } \\
\text { role }\end{array}$ & $\begin{array}{l}\text { EA synchronizes the PhP } \\
\text { based on other elements }\end{array}$ \\
\hline ME & $\begin{array}{l}\text { Active } \\
\text { entity }\end{array}$ & $\begin{array}{l}\text { It is the product in } \\
\text { circulation. When the } \\
\text { PhP ends, the ME sends } \\
\text { a synchronization request } \\
\text { to the EA with its new } \\
\text { state }\end{array}$ \\
\hline $\mathrm{PhP}$ & Task & $\begin{array}{l}\text { It's a task or a physical } \\
\text { activity to be handle by } \\
\text { the EA }\end{array}$ \\
\hline Resource & $\begin{array}{l}\text { Passive } \\
\text { resource }\end{array}$ & $\begin{array}{l}\text { It is an allocated resource } \\
\text { to EA to perform its task. }\end{array}$ \\
\hline $\begin{array}{l}\text { Organizational } \\
\text { knowledge }\end{array}$ & $\begin{array}{l}\text { Knowledg } \\
\text { e }\end{array}$ & $\begin{array}{l}\text { Each EA owns a list that } \\
\text { contains information } \\
\text { about others EA from the } \\
\text { same SSC. This list } \\
\text { stores knowledge about } \\
\text { the name of the EA, the } \\
\text { task that it performs and } \\
\text { its resources. }\end{array}$ \\
\hline
\end{tabular}

Then, on the basis of these concepts, the synchronization protocol consists of (Figure 5):

- An Executive Agent (EA) receives a request and reacts according to its type. Three kinds of request can be distinguished: a ME request, a collaborative request from another EA or a negative response to a collaborative action initiated by this one.
- If the request is a negative response to a collaborative demand that the EA initiated. In this case, the EA send a request to the coordinator agent of the monitoring system.

- If the request is a synchronization need coming from the Moving Entity (ME) or a collaborative request from another initiator agent, EA checks the availability of the concerned resources.

- If the resource is available, the EA carries out its task, updates the state of ME and informs the other agents from the executive system and the coordinator agent of the end of action.

- If the resource is unavailable and the EA has been solicited by another executive agent to achieve the task, it sends a failure request to the initiator.

- If the resource is unavailable and the EA is in charge of the task then it seeks in its organizational knowledge an agent from the execution system of the SSC that might have the needed resource.

- If the agent finds in its organizational knowledge an agent that can handle the task, it delegates the responsibility of the task. In this case, the collaboration process of the concerned agent will be activated and follows the same sequence.

- If the agent does not find another agent having the needed resource to handle the task, it sends a request to the coordinator agent. This agent is a monitoring agent (MA) that receives requests from Execution System. MA diffuses the information to other monitoring agents of the SSC in order to find a solution.

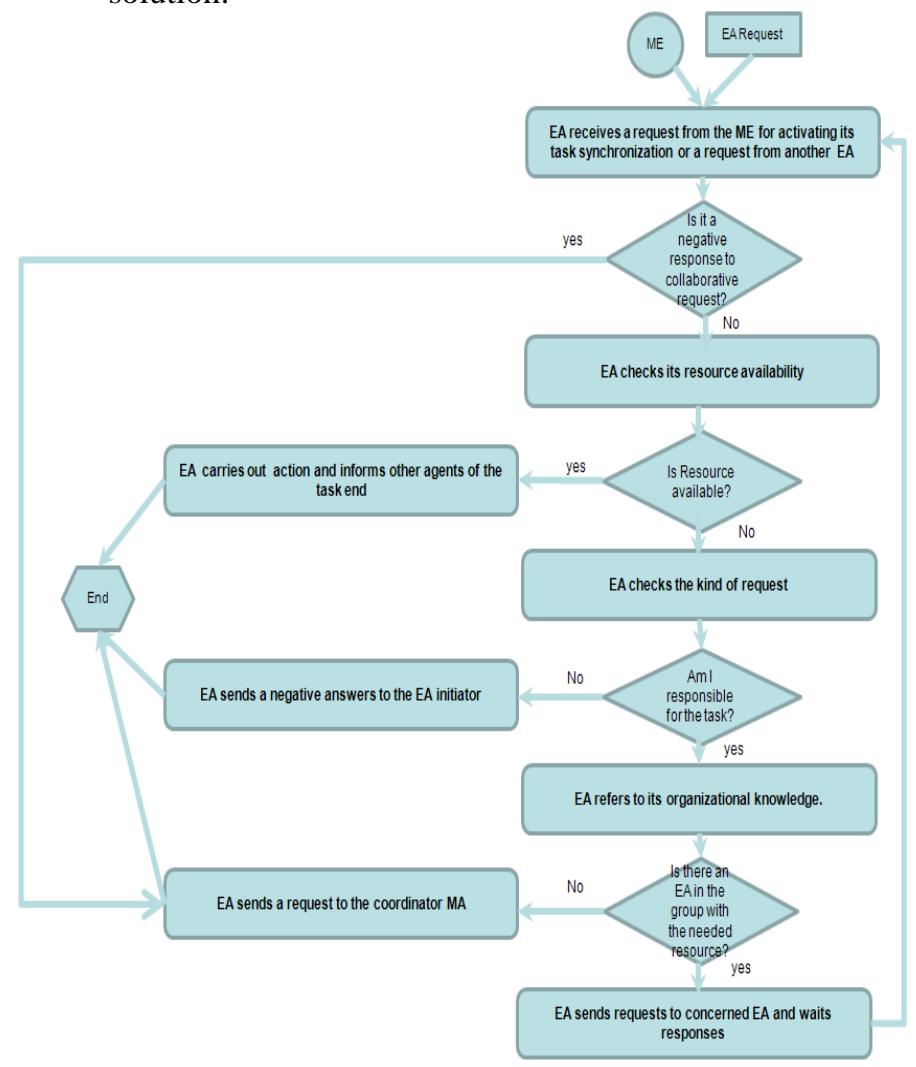

Figure 5. EA Behavior 


\section{Physical System Control Protocol}

This protocol is based on performance evaluation. At the physical process synchronization end, each EA updates the indicators values that evaluate the performance of its activity and related resources. Then, the table 3 summarises the different concepts and their role in the control process.

According to the table 3 , the behaviour of involved concepts constitutes the "Control physical system process":

- At the end of its synchronization task, the EA evaluates the performance of its activity and related resources (the allocated space of the environment to the EA).

- According to this perception, the EA refers to the indicator base in order to detect a perturbation.

- If the EA finds an indicator deviation, it seeks the cause of the perturbation.

- If the deviation is a common situation, the EA selects the appropriate action plan to solve the problem and applies it to the environment.

- If a new situation occurs, the EA sends a failure control message to the coordinator MA. Then, the MA spreads the information in the monitoring system.

Table 3. Role of concepts in physical control protocol

\begin{tabular}{|c|c|c|}
\hline $\begin{array}{l}\text { Domain } \\
\text { concepts }\end{array}$ & $\begin{array}{c}\text { Multiagent } \\
\text { concepts }\end{array}$ & Role \\
\hline EA & $\begin{array}{l}\text { Reactive } \\
\text { agent with } \\
\text { executive } \\
\text { role }\end{array}$ & $\begin{array}{l}\text { EA evaluates the } \\
\text { performance of the } \\
\text { physical system and } \\
\text { acts on it } \\
\text { consequently }\end{array}$ \\
\hline Indicator & Belief & $\begin{array}{l}\text { Belief of agent about } \\
\text { the optimal } \\
\text { performance state of } \\
\text { the environment }\end{array}$ \\
\hline Action & Plan & $\begin{array}{l}\text { A reactive plan } \\
\text { established by the } \\
\text { monitoring system. } \\
\text { EA reacts to the } \\
\text { perception from the } \\
\text { environment } \\
\text { according to the plan }\end{array}$ \\
\hline Environment & Environment & $\begin{array}{l}\text { It is the allocated } \\
\text { space to the EA to } \\
\text { act on it }\end{array}$ \\
\hline MA & $\begin{array}{l}\text { Cognitive } \\
\text { agent with a } \\
\text { coordinator } \\
\text { role }\end{array}$ & $\begin{array}{l}\text { MA receives the } \\
\text { failure message from } \\
\text { the EA when an } \\
\text { uncommon } \\
\text { perturbation occurs }\end{array}$ \\
\hline
\end{tabular}

The figure 6 describes the sequence diagram of the "Physical Process Control” using UML formalism.

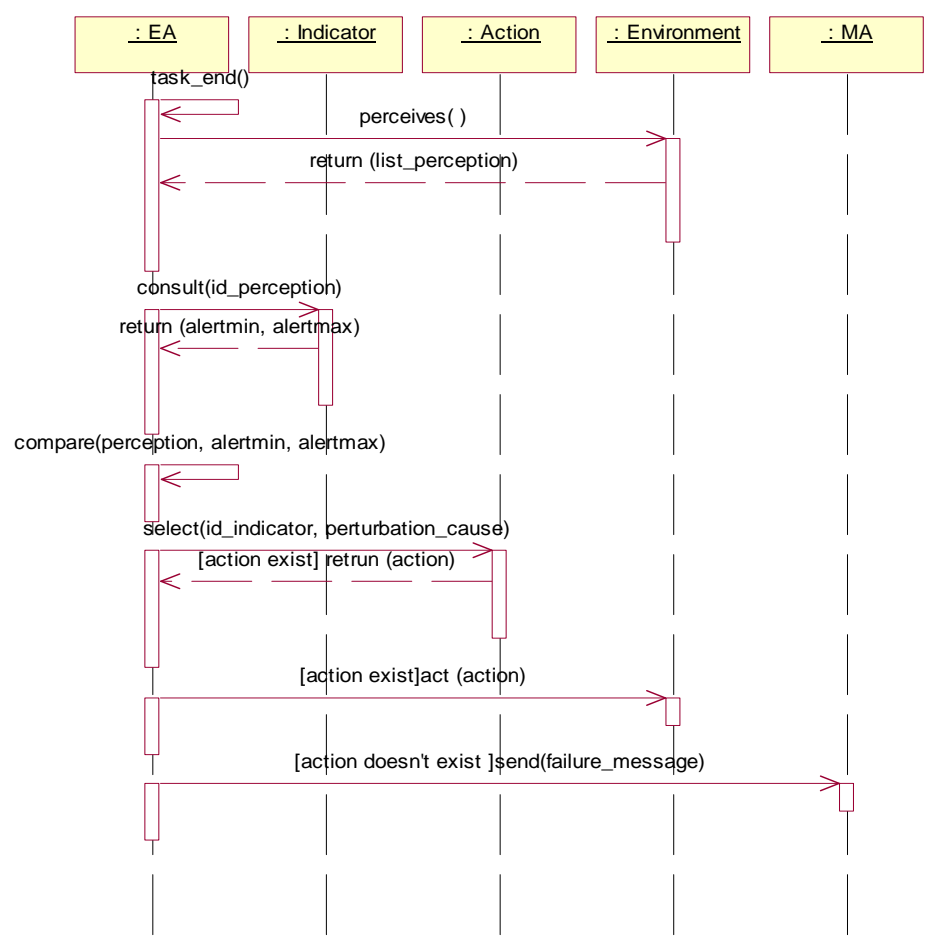

\section{Figure 6. Sequence Diagram of Physical process control}

\section{CONCLUSION}

This article presents a metamodel describing the supply chain in the SMEs mechatronic context. Our approach combines this domain metamodel (scope of research) to the multiagent one based on the ArchMDE development process. This process allows the separation of the architecture building and the study of the concepts behaviour based on multiagent paradigm in order to facilitate and control the software development. This work describes how to generate the domain metamodel, the multiagent one and the merging one. Then, on the basis of the obtained concepts, we propose two processes in order to synchronize and control dynamically the physical flow.

There are a number of issues that we intend to address in future work, the most direct of which is the implementation of a collaborative process in the monitoring layer (intelligent layer of the SSC) and coordination processes between different SSC that constitute the global supply chain.

\section{REFERENCES}

Azaiez S., 2007. Approche Dirigée par les modèles pour le développement de systèmes multi-agents. Thèse de l'Université de Savoie, Spécialité Informatique. December 11, Annecy le vieux, France. 
Azaiez S., Habchi G., Huget M.P., Pralus M. and Tounsi J., 2007. Multiagent oriented modelling and simulation for manufacturing systems control. INDIN 2007, $5^{\text {th }}$ IEEE International Conference on Industrial Informatics, July 23-27. Vienna, Austria.

Bratman M.E, Israel D.J., Pollack M., 1998. Plans and resource-bounded practical reasoning. Computational Intelligence, 4, pp 349-355.

Brooks R.A., Intelligence without representation, Artificial Intelligence, 47: 139-160. 1991.

Bussmann S., Jennings N.R, Wooldridge M., 2004. Multiagent Systems for Manufacturing Control: A Design Methodology, Springer Series on Agent Technology, Springer.

Chopra S. and Meindl P., 2001. Supply Chain Management: strategy planning and operation. Upper Saddle River, NJ: Prentice-hall.

Cooper M., Lambert D.M. and Pagh J.D., 1997. Supply chain management: more than a new name for logistics. International Journal of Logistics Management, vol 18, n², pp. 1-13.

Demazeau Y., 1996. "Vowels", Invited lecture, IWDAIMAS96.

Fischer K., Müller J.P., Pischel M., 1995. Unifying control in a layered agent architecture. IJCAI95, Agent Theory, Architecture and language workshop, pp 240-252

Julien P.A., 1997. Les PME bilan et perspectives. $2^{e}$ edition, Economica, Paris, France.

Kent S., 2002. Model-driven Engineering, IFM 2002, vol. 2335 of LNCS, Springer-Verlag, pp. 286-298.

Stevens G.C., 1989. Integrating the supply chain. International Journal of Physical Distribution and Materials Management, 19, pp 3-8.

Thierry C. 2003. Gestion des chaînes logistiques : Modèle et mise en œuvre pour l'aide à la décision à moyen terme. Accreditation to supervise research. University of Toulouse II.

Tounsi J., Boissière J., Habchi G., 2008. A conceptual model for SME Mechatronics supply chain. $6^{\text {th }}$ International Industrial Simulation Conference (ISC’08), Lyon, France, pp. 273-280.

Tounsi J., Azaiez S., Habchi G., Boissière J., 2009. A multiagent approach for modelling SMEs mechatronic supply chains. $13^{\text {th }}$ IFAC Symposium on Information Control Problems in Manufacturing. (accepted)

Villarreal Lizarraga, C.L., Dupont L., Gourg D., Pingaud H., 2005. Contributing to management of shared projects in SMEs manufacturing clusters. $18^{\text {th }}$ International Conference on Production Research (ICPR-18), Salerno, Italy.

Wooldridge M., 1999. Intelligent Agents. Multiagents Systems, Weiss G., Ed:MIT Press.

Wooldridge M., 2002. An introduction to Multiagent Systems. Jonh Wiley \& Sons, February.

Wooldridge M. and Jennings N.R 1999. The cooperative Problem-Solving Process. Journal of Logic Computational., Vol. 9, pp. 563-592. 